\title{
Substance Use Disorders Education: Are We Heeding the Call?
}

\section{Mary K. Morreale ${ }^{1}$ (D) Richard Balon ${ }^{1} \cdot$ Rashi Aggarwal $^{2} \cdot$ John Coverdale $^{3} \cdot$ Eugene Beresin $^{4}$. Anthony P. S. Guerrero ${ }^{5}$ - Alan K. Louie ${ }^{6}$ - Adam M. Brenner ${ }^{7}$}

Received: 31 January 2020 / Accepted: 7 February 2020 / Published online: 27 February 2020

(C) Academic Psychiatry 2020

According to the 2018 National Survey on Drug Use and Health [1], over 20 million people in the USA meet criteria for some type of substance use disorder. Despite the fact that most physicians encounter patients with substance use disorders at some point during their careers, clear evidence shows that prevention, diagnosis, and treatment are less than adequate $[2,3]$. These findings are saddening, with unintentional drug overdoses listed as a leading cause of death in the USA [4].

Academic psychiatrists are responsible for assisting in education on substance use disorders for medical students, psychiatry residents, and residents in other specialties. Many obstacles to this education occur, including a shortage of faculty certified in addiction psychiatry or medicine, lack of time for new curricular content, and a need for incentives to encourage participation in fellowships [5]. We must think creatively about how to enhance our efforts in education and to ensure that all physicians - irrespective of degree of formal specialization in addictions - receive adequate preparation for caring for patients with substance use disorders. Several areas for improvements include increased curricular time devoted to education and training, more interprofessional learning opportunities, and greater first-person experiences with successful treatment of this patient population $[5,6]$. In the February 2020 issue of Academic Psychiatry, these areas are further explored in a collection of seven articles [7-12].

Mary K. Morreale

mmorreale@med.wayne.edu

1 Wayne State University, Detroit, USA

2 Rutgers New Jersey Medical School, Newark, USA

3 Baylor College of Medicine, Houston, USA

4 Harvard Medical School, Boston, USA

5 University of Hawai'i John A. Burns School of Medicine, Honolulu, USA

6 Stanford University, Stanford, USA

7 University of Texas Southwestern Medical Center, Dallas, USA
Historically, medical schools devote less time to substance use disorders than similarly prevalent illnesses, and not surprisingly, many physicians are left feeling unprepared to care for patients with these conditions [2]. This lack of preparedness is apparent in the study "Smoking Cessation Prescribing and Referral Practices among Psychiatry Residents" [7], which found that nearly half of the residents surveyed had never prescribed either varenicline or bupropion for nicotine use disorders. Over $60 \%$ of respondents reported feeling somewhat or extremely uncomfortable with these medications. This finding remained throughout all years of training, which suggests a potential practice gap wherein physicians in training are exposed to numerous patients who are suffering from addiction but have few curricular hours dedicated to their identification and management [13]. In addition, it signals that a 1-h didactic and informal teaching during clinical activities is likely insufficient for promoting confidence in early career physicians.

Clearly, an expansion of workforce is needed to care for this patient population given the scope of the substance use epidemic in the USA. Although Rakocevic et al. [8] note that the number of fellowship positions accredited by the Accreditation Council for Graduate Medical Education (ACGME) in addiction psychiatry is at an "all-time high" of 132 , only $64 \%$ of these spots were actually filled $[8,14]$. Encouraging psychiatry residents to pursue subspecialty training may be one part of the solution, but additional education of non-psychiatric physicians and other health care providers via addiction medicine training pathways is also necessary.

In the article "Behavior Change Counseling of Patients with Substance Use Disorders by Health Professions Students" [9], the coordinated efforts of faculty from medicine, nursing, pharmacy, social work, and physician assistant programs were found to be helpful in both providing increased care for patients and shifting learners' attitudes. The authors developed a 6 -h curriculum that included didactics on the assessment and treatment of substance use disorders, efforts to increase empathy, and an examination of personal bias, which was followed by 
observation of students counseling a patient utilizing a behavior change approach. The included students demonstrated a high overall level of performance with displays of openness, sensitivity, empathy, and respect. In addition, when the involved patients were queried immediately following this intervention, more than $90 \%$ expressed a willingness for continued treatment.

Efforts to improve attitudes toward patients with substance use disorders are vital because health professionals can exhibit stigmatizing beliefs toward patients with these illnesses [15-17]. This concern was reflected clearly in the qualitative exploration of medical student essays done by Clark et al. [10]. In this work, third-year medical students were asked to write about a clinical encounter that was "troubling, affirming or thought provoking." Of those that discussed substance use, the themes that emerged were mostly negative, including malingering, inadequate treatment of pain, unruly behaviors, and frank aggression. As the authors note, "the substance abuse essays seem to be reflecting on negative experiences, rather than expressing optimism or affirming experiences." Whether these results would have differed if the students were rotating through psychiatry at the time of writing is unclear but unlikely, given findings that psychiatry residents' attitudes toward patients with substance use disorders worsen over time in practice [17].

Unlike the essays mentioned above, both "Compassion Saves Lives" [11] and "Just Here for Detox" [12] maintain a more hopeful tone. In the former [11], the author succinctly depicts, in the form of a poem, what an individual with a substance use disorder might experience emotionally while moving from detoxification to relapse and finally recovery. In the latter [12], a psychiatry intern eloquently writes about reconnecting with a patient first met during medical school. The author describes both the vulnerability that she experienced witnessing the patient's failed attempt at sobriety and the "dichotomy" in medicine that encourages physicians to connect with their patients without expressing emotion. The title "Just Here for Detox" recognizes the negative attitudes that patients with substance use disorders face. It is heartening to read a compassionate response to this stigma in the ending paragraph: "He was not just here for detox...He was here for a second chance, and I was ready to help him take that next step" [12].

Taken together, this collection offers us valuable information on the current state of education related to substance use disorders and provides insight into medical student and resident perspectives on treating patients who are diagnosed with these diseases. The collection also alerts us to the obstacles we must consider when developing educational interventions, such as stigma and the need to move beyond standard curricula. Potential solutions are addressed as well, for instance, the targeted intervention that successfully improved learners' attitudes [9]. As academic psychiatrists, we need to encourage residents to pursue additional training related to addiction, either through formal fellowship or elective exposure during general residency training [18]. We need an enlightened educational leadership to assist in implementing an evidencebased curriculum throughout medical school, residency, and fellowship training [19]. Given the scope of substance use disorders in the USA, psychiatrists will not be able to approach this education alone but must include providers outside of psychiatry in our efforts. When addressing deficits in education related to substance use disorders in 2016, Ram and Chisolm [6] wrote, "The time is now." Four years later, are we heeding this call?

\section{Compliance with Ethical Standards}

Conflict of Interest The authors declare that they have no conflict of interest.

\section{References}

1. Substance Abuse and Mental Health Services Administration. 2018 NSDUH Annual National Report. Available at https://www. samhsa.gov/data/report/2018-nsduh-annual-national-report. Accessed 31 Jan 2020.

2. Miller NS, Sheppard LM, Colenda CC, Magen J. Why physicians are unprepared to treat patients who have alcohol- and drug-related disorders. Acad Med. 2001;76(5):410-8.

3. Volkow ND, Boyle M. Neuroscience of addiction: relevance to prevention and treatment. Am J Psychiatry. 2018;175(8):729-40.

4. Centers for Disease Control and Prevention. Opioid Overdose. Available at https://www.cdc.gov/drugoverdose/. Accessed 13 Feb 2020.

5. Lembke A, Humphreys K. The opioid epidemic as a watershed moment for physician training in addiction medicine. Acad Psychiatry. 2018;42:269-72.

6. Ram A, Chisolm MS. The time is now: improving substance abuse training in medical schools. Acad Psychiatry. 2016;40:454-60.

7. Kleinman RA, Kendra MS, De Golia SG. Smoking cessation prescribing and referral practices among psychiatry residents. Acad Psychiatry. 2019:1-3. https://doi.org/10.1007/s40596-019-01104-z.

8. Rakocevic DB, DeJong SM, Saxon AJ, Renner JA Jr, Schwartz AC. A guide for applying to addiction psychiatry fellowship. Acad Psychiatry. 20196:1-6. https://doi.org/10.1007/s40596-01901144-5.

9. Muzyk A, Mullan P, Andolsek K, Derouin A, Smothers Z, Sanders $\mathrm{C}$, et al. Behavior change counseling of patients with substance use disorders by health professions students. Acad Psychiatry. 2019:16. https://doi.org/10.1007/s40596-019-01093-z.

10. Clark T, Camp M, Sadler J. "He bore it like a scarlet letter": medical student reflections on substance use disorders. Acad Psychiatry. 2020. https://doi.org/10.1007/s40596-020-01194-0.

11. Proctor SL. Compassion Saves Lives. Acad Psychiatry. 2020. https://doi.org/10.1007/s40596-020-01189-x.

12. Wendt A. Just here for detox. Acad Psychiatry. 2019 Aug 12:1-2. https://doi.org/10.1007/s40596-019-01101-2.

13. Tetrault JM, Petrakis IL. Partnering with psychiatry to close the education gap: an approach to the addiction epidemic. J Gen Intern Med. 2017;32:1387-9.

14. American Psychiatric Association. 2018 Resident/Fellow Census. Available at https://www.psychiatry.org/File\%20Library/ 
Residents-MedicalStudents/Residents/APA-Resident-Census2019.pdf. Accessed 31 Jan 2020.

15. van Boekel LC, Brouwers EP, van Weeghel J, Garretsen HF. Stigma among health professionals towards patients with substance use disorders and its consequences for healthcare delivery: systematic review. Drug Alcohol Depend. 2013;131(1-2):23-35.

16. Lindsay DL, Hagle H, Lincoln P, Williams J, Luongo PF. Exploring medical students' conceptions of substance use: a follow-up evaluation. Subst Abus. 2017;38(4):464-7.

17. Avery J, Han BH, Zerbo E, Wu G, Mauer E, Avery J, et al. Changes in psychiatry residents' attitudes towards individuals with substance use disorders over the course of residency training. Am J Addict. 2017;26:75-9.

18. Balon R. Subspecialty training: time for change. Acad Psychiatry. 2017;41:558-60.

19. Frances R. Help wanted: medical educators in addiction psychiatry. Acad Psychiatry. 2018;42:273-6.

Publisher's Note Springer Nature remains neutral with regard to jurisdictional claims in published maps and institutional affiliations. 